\title{
Maculergithus, a new subgenus in Gergithus Schumacher, 1915 with two new species from northern Vietnam (Hemiptera: Fulgoromorpha: Issidae)
}

\author{
Jérôme CONSTANT ${ }^{1, *}$ \& Hong-Thai PHAM ${ }^{2}$ \\ ${ }^{1}$ Royal Belgian Institute of Natural Sciences, O.D. Phylogeny and Taxonomy, Entomology, \\ Vautier street 29, B-1000 Brussels, Belgium. \\ ${ }^{2}$ Vietnam National Museum of Nature, Vietnam Academy of Science and Technology, \\ 18 Hoang Quoc Viet Street, Hanoi, Vietnam. \\ *Corresponding author: jerome.constant@naturalsciences.be \\ ${ }^{2}$ Email: phamthai@,vnmn.vast.vn \\ ${ }^{1}$ urn:Isid:zoobank.org:author:6E6072A1-9415-4C8D-8E60-2504444DB290 \\ ${ }^{2}$ urn:1sid:zoobank.org:author:E34CB863-7E3B-4E8F-8738-B41C07D9F5F9
}

\begin{abstract}
The new subgenus Maculergithus subgen. nov. is established to accommodate two new species of the genus Gergithus Stål, 1870 (Issinae, Hemisphaeriini): G. (Maculergithus) tamdao subgen. et sp. nov. and G. (Maculergithus) luteomaculatus subgen. et sp. nov. from Tam Dao National Park in North Vietnam. Two more species from Hainan, China, G. multipunctatus Che, Zhang \& Wang, 2007 and G. nonomaculatus Meng \& Wang, 2012 are also placed in Maculergithus subgen. nov. A fifth species from Hainan, yet undescribed and erroneously identified as G. multipunctatus in recent papers also belongs to this new subgenus. Illustrations of habitus, morphological details and male genitalia together with a distribution map and an identification key to the species of Maculergithus subgen. nov. are provided. Four species of the genus Gergithus are now recorded in Vietnam. A rectificative note on the misinterpretation of G. multipunctatus in recent publications on Issidae is also provided.
\end{abstract}

Keywords. Global Taxonomic Initiative, Tonkin, planthopper, Fulgoroidea, China.

Constant J. \& Pham H.-T. 2016. Maculergithus, a new subgenus in Gergithus Schumacher, 1915 with two new species from northern Vietnam (Hemiptera: Fulgoromorpha: Issidae). European Journal of Taxonomy 198: 1-16. http://dx.doi.org/10.5852/ejt.2016.198

\section{Introduction}

In the family Issidae Spinola, 1839, the tribe Hemisphaeriini Melichar, 1906 currently groups 17 genera and 184 species (Bourgoin 2016). It is mainly a Sino-Japanese and Oriental taxon, extending in its borders into the Eastern Palaearctic and Oceanian realms (Holt et al. 2013). The genus Gergithus Stål, 1870 (Issinae, Hemisphaeriini) currently counts 60 species and 2 subspecies distributed in South-East Asia (Bourgoin 2016). It was erected by Stål (1870) to include the type species Hemisphaerius schaumi Stål, 1855, a species described by Stål (1855) from Taprobane Island on the southern coast of Sri Lanka, 
while Melichar (1906) in his revision of the Issidae stated that Stål's type specimen bears a label "Pulo Penang" (in Malaysia). The genus Ishiharanus was later described by Hori (1969) to accommodate one species originally described from Japan in Gergithus, G. iguchii Matsumura, 1916. The separation of Ishiharanus from Gergithus was based on coloration, the short pronotum and the smooth frons in Ishiharanus. Che et al. (2007) did not follow this view and proposed Ishiharanus as a junior synonym of Gergithus. In recent years, the taxonomic effort concerning the family Issidae allowed the description of 6 species of Gergithus from Taiwan (Chan \& Yang 1994), and 11 species from China (Che et al. 2007; Zhang \& Che 2009; Meng \& Wang 2012).

Only two species, G. gravidus Melichar, 1906 and G. iguchii Matsumura, 1916 are currently recorded from Vietnam (Gnezdilov \& Constant 2012; Gnezdilov et al. 2014). The former was originally described by Melichar (1906) from Northern Vietnam and the latter, described from Japan, was mentioned from Northern Vietnam by Fennah (1978).

The study of recently collected material in the framework of our Global Taxonomic Initiative project "A step further in the Entomodiversity of Vietnam" revealed two new species of Gergithus from Tam Dao National Park. They are closely related to G. multipunctatus Che, Zhang \& Wang, 2007 and G. nonomaculatus Meng \& Wang, 2012 which were described from Hainan Island (China) (Che et al. 2007; Meng \& Wang 2012).

Despite the illustrations given by Che et al. (2007) in their description of G. multipunctatus, Chen et al. (2014) as well as Guo \& Chen (2015) mistook the species for another one, as yet undescribed, which does not show the typical yellow round spot on the frons and has very different male genitalia. Hence, the photographs and drawings in both latter papers do not refer to G. multipunctatus but to a new species with frons entirely black-brown on dorsal half and originating from Wuzhishan, Hainan (China).

The present paper aims at describing a new subgenus in Gergithus and two new species from Northern Vietnam belonging to the new subgenus, and to clarify some taxonomic issues concerning Chinese species included in the new subgenus. We also provide an illustrated identification key to the species, and discuss the currently recorded distribution of the subgenus.

\section{Material and methods}

The specimens were captured by hand using small transparent vials with which they were slowly covered or collected by sweeping the lower vegetation in the forest.

The genitalia were extracted after boiling the abdomen about one hour in a $10 \%$ solution of potassium hydroxide $(\mathrm{KOH})$ at about $100^{\circ} \mathrm{C}$. Some drops of saturated alcoholic Chlorazol black solution were added for contrasting (Carayon 1969). The pygofer was separated from the abdomen and the aedeagus dissected with a needle blade for examination. The whole was then placed in glycerine for preservation in a tube attached to the pin of the specimen.

The measurements were taken as in Constant (2004) and the following abbreviations are used:

$\mathrm{BF}=$ maximum breadth of the frons

$\mathrm{BTg}=$ maximum breadth of the tegmen

$\mathrm{BV}=$ maximum breadth of the vertex

$\mathrm{LF}=$ length of the frons in median line

$\mathrm{LTg}=$ maximum length of the tegmen

LT = total length (apex of head to apex of tegmina)

$\mathrm{LV}=$ length of the vertex in median line 
The metatibiotarsal formula gives the number of spines on (side of metatibia) apex of metatibia/apex of first metatarsus/apex of second metatarsus

For each picture a number of photographs were taken with a Canon 700D camera equipped with a Tamron $90 \mathrm{~mm}$ Macro lens and staked with Combine Z software. They were optimized with Adobe Photoshop CS3. Observations were done with a Leica MZ8 stereo microscope.

The Chinese material was not available for study and we based our observations for Gergithus (Maculergithus) multipunctatus Che, Zhang \& Wang, 2007 and Gergithus (Maculergithus) nonomaculatus Meng \& Wang, 2012 on the published illustrations (see also FLOW: http://hemiptera-databases.org/fl ow/?page=explorer\&db=flow\&lang=en\&card=taxon\&rank=species\&id=16949 and http://hemipteradatabases.org/flow/?page=explorer\&db=flow\&lang=en\&card=taxon\&rank=species\&id=17635).

Acronyms used for the collections:

RBINS = Royal Belgian Institute of Natural Sciences, Brussels, Belgium

VNMN $=$ Vietnam National Museum of Nature, Hanoi, Vietnam

\section{Results}

Class Hexapoda Blainville, 1816

Order Hemiptera Linnaeus, 1758

Suborder Auchenorrhyncha Duméril, 1806

Infraorder Fulgoromorpha Evans, 1946

Superfamily Fulgoroidea Latreille, 1807

Family Issidae Spinola, 1839

Subfamily Issinae Spinola, 1839

Tribe Hemisphaeriini Melichar, 1906

Genus Gergithus Stål, 1870

Gergithus Stål, 1870: 756. Type species: Hemisphaerius schaumi Stål, 1855 by original designation. Ishiharanus Hori, 1969: 49 [synonymized by Che et al. 2007: 611]. Type species: Gergithus iguchii Matsumura, 1916 by original designation.

The genus can be separated from other Hemisphaeriini with the key to the genera of Hemisphaeriini proposed by Sun et al. (2012) with the following distinctive set of characters for Gergithus: (1) posterior wing longer than half length of tegmen; (2) frons smooth without median carina or row of tubercles along lateral margin.

Subgenus Maculergithus subgen. nov. urn:1sid:zoobank.org:act:C13CCE8B-1279-4FF8-8464-30553592E4B3

\section{Type species}

Gergithus (Maculergithus) tamdao subgen. et sp. nov.

\section{Diagnosis}

The new subgenus Maculergithus subgen. nov. in Gergithus is here erected for the species sharing the combination of the following characters:

(1) ground colour black-brown;

(2) tegmina with numerous yellow spots separated from one another;

(3) frons with a broad yellow transverse band above fronto-clypeal suture; 
(4) mesonotum with yellow spot on each lateral angle;

(5) posterior margin of pygofer of male genitalia strongly rounded posterad in lateral view;

(6) anal tube elongate, truncate apically and with apicolateral angles projecting posteroventrally.

\section{Etymology}

The name is formed by the combination of "maculatus" (adj., Latin) = spotted and "Gergithus", the genus to which pertains the new subgenus. It is masculine in gender.

\section{Species included}

Gergithus (Maculergithus) luteomaculatus subgen. et sp. nov. (Vietnam, Tam Dao National Park), Gergithus (Maculergithus) multipunctatus Che, Zhang \& Wang, 2007 (China, Hainan Island: Jianfeng Mountain),

Gergithus (Maculergithus) nonomaculatus Meng \& Wang, 2012 (China, Hainan Island: Bawangling Mountain),

Gergithus (Maculergithus) tamdao subgen. et sp. nov. (Vietnam, Tam Dao National Park).

The subgenus currently contains 4 species, but an undescribed species from Hainan Island (Wuzhishan), illustrated and erroneously referred to as G. multipunctatus in both Chen et al. (2014: 56) and Guo \& Chen (2015), also belongs to the group.

Pending additional new groupings (see discussion), all other species are currently retained in the nominal subgenus Gergithus (Gergithus) Stål, 1870.

\section{Distribution}

Currently known distribution includes Hainan Island (China) and Tam Dao massif (North Vietnam) (Fig. 1).

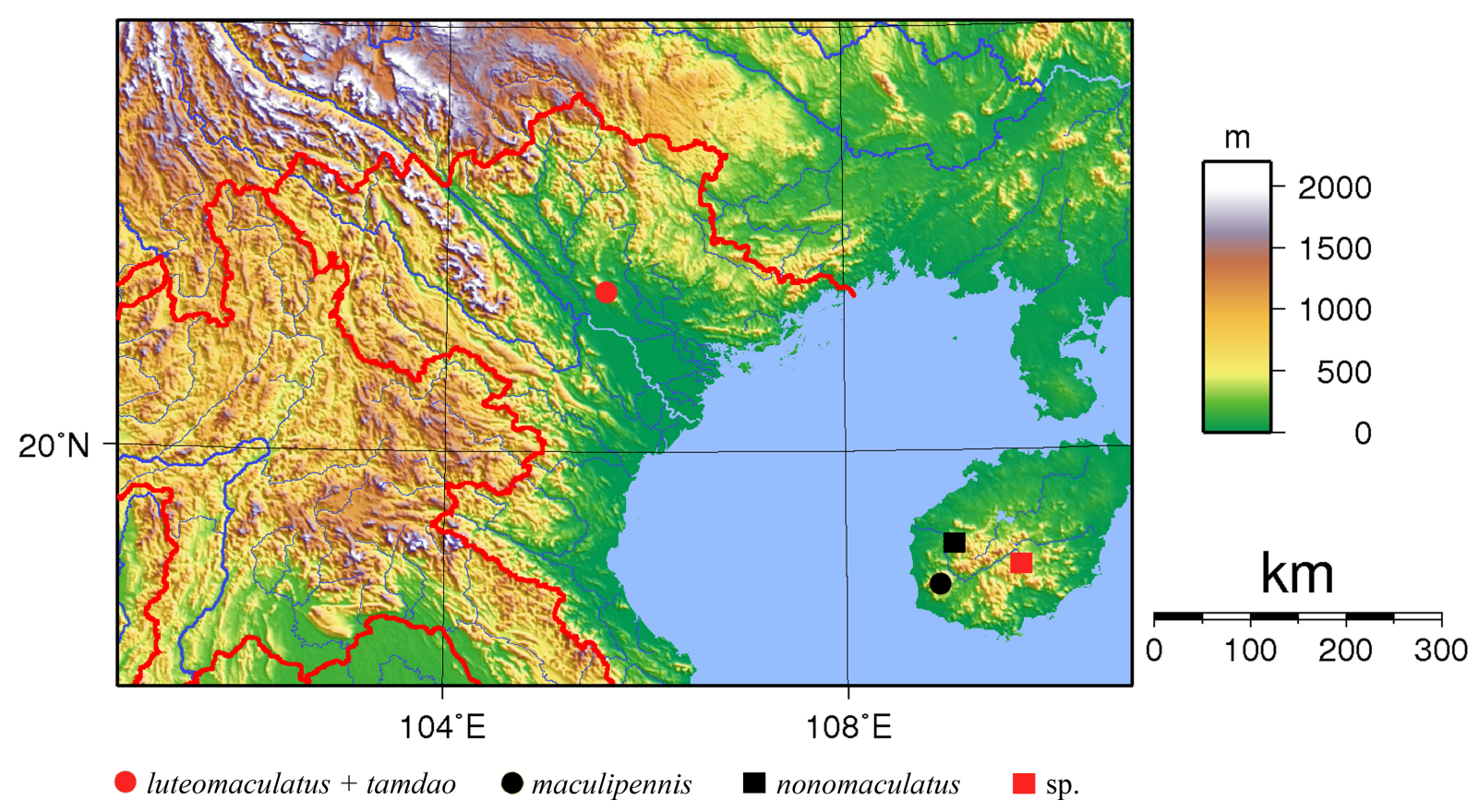

Fig. 1. Distribution map of the species of Gergithus (Maculergithus) subgen. nov. in North Vietnam and Hainan. 


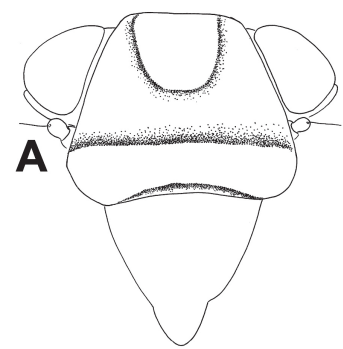

B
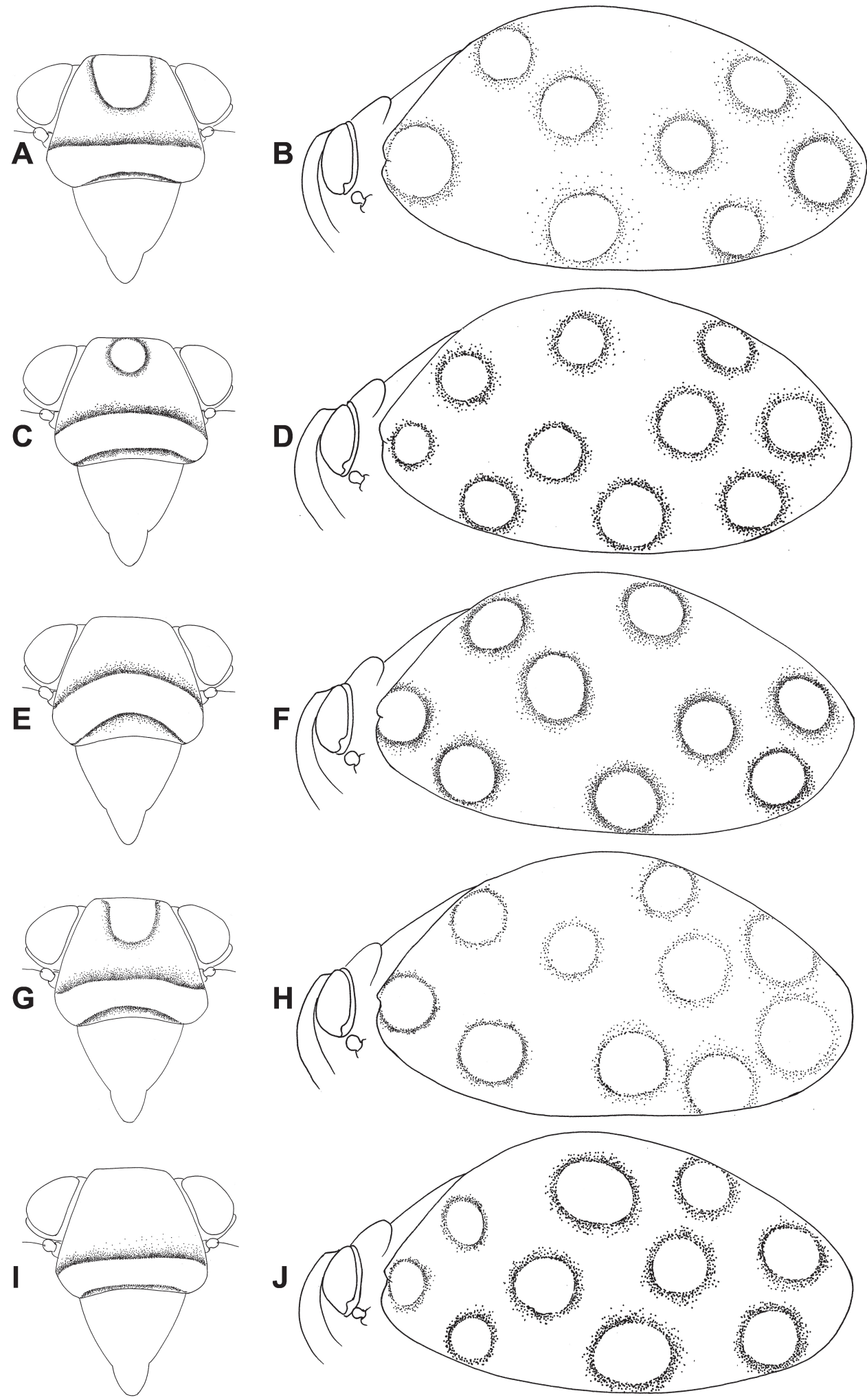

Fig. 2. Gergithus (Maculergithus) subgen. nov., schema of maculation of frons and left tegmen. A-B. Gergithus (Maculergithus) luteomaculatus subgen. et sp. nov. C-D. Gergithus (Maculergithus) multipunctatus Che, Zhang \& Wang, 2007. E-F. Gergithus (Maculergithus) nonomaculatus Meng \& Wang, 2012. G-H. Gergithus (Maculergithus) tamdao subgen. et sp. nov. I-J. Gergithus (Maculergithus) sp. (drawings by J. Caudron, RBINS; C-F, I-J based on illustrations of original descriptions). 


\section{Biology}

All species seem to live in forested zones of mountainous regions.

\section{Identification key to the species of Gergithus (Maculergithus):}

1. Vertex brown; yellow round spot on frons near dorsal margin (Fig. 2C); tegmina with 10 yellow spots in total (Fig. 2D). Recorded from Jianfeng Mountain, Hainan, China

. Gergithus (Maculergithus) multipunctatus Che, Zhang \& Wang, 2007

- Vertex yellow; yellow spot of frons extending to vertex, or no yellow spot on dorsal half of frons;

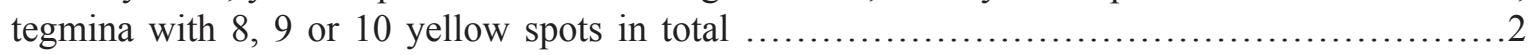

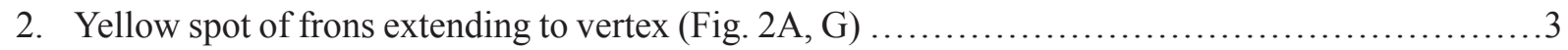

- Dorsal half of frons brown without yellow spot (Fig. 2E, I) ..............................

3. Tegmina with 2 yellow spots along sutural margin and 8 yellow spots in total (Fig. 2B). Recorded from Tam Dao N.P., Vietnam ...................G. (Maculergithus) luteomaculatus subgen. et sp. nov.

- Tegmina with 3 yellow spots along sutural margin and 10 yellow spots in total (Fig. 2H). Recorded from Tam Dao N.P., Vietnam ........................G.(Maculergithus) tamdao subgen. et sp. nov.

4. Tegmina with 9 yellow spots in total (Fig. 2F). Recorded from Bawangling Mountain, Hainan, China ................................. (Maculergithus) nonomaculatus Meng \& Wang, 2012

- Tegmina with 10 yellow spots in total (Fig. 2J). Recorded from Wuzhishan, Hainan, China ............ G. (Maculergithus) sp.

Gergithus (Maculergithus) luteomaculatus subgen. et sp. nov. urn:1sid:zoobank.org:act:8E0B399D-54DE-4657-8150-299082810E09

Figs 1, 2A-B, 3-4

\section{Diagnosis}

The species can be recognized by the following combination of characters: (1) frons with a yellow spot along dorsal margin; (2) vertex yellow; (3) 2 yellow spots on tegmina along sutural margin; (4) tegmina with 8 yellow spots in total.

\section{Etymology}

The species epithet is formed by the juxtaposition of luteus (adj., Latin) = yellow and maculatus (adj., Latin $)=$ spotted. It refers to the yellow spots on the mesonotum and tegmina of the species.

\section{Type material}

Holotype

VIETNAM: $\widehat{\jmath}$ (dissected, Fig. 3): [Coll. I.R.Sc.N.B., Vietnam, Tam Dao N.P., 25-30.vii.2011, day collecting, Leg. J. Constant \& J. Bresseel, I.G.: 31.933] (RBINS).

\section{Paratype}

VIETNAM: : [VP-VQG Tam Dao, R900, 15/VII/01] (VNMN).

\section{Description}

Measurements and ratios. LT: $\widehat{O}(\mathrm{n}=1): 6.4 \mathrm{~mm}$; + $(\mathrm{n}=1): 7.5 \mathrm{~mm}$. Ratio BV/LV=4.3; $\mathrm{LF} / \mathrm{BF}=0.85$; $\mathrm{LTg} / \mathrm{BTg}=1.5$. 
HEAD. Vertex slightly excavate, bright yellow (Fig. 3A). Frons smooth and convex, largely visible from above, black-brown with broad transverse bright yellow band slightly above clypeo-frontal suture, and rounded bright yellow spot along dorsal margin, not reaching dorsolateral angles (Fig. 3A-D). Genae black-brown, bright yellow under antennae (Fig. 3C). Clypeus smooth, slightly carinate subapically, black-brown with medio-basal diffuse small brown patch (Fig. 3B, D). Labium dark brown, reaching median coxae, with last segment narrower and shorter than penultimate. Antennae black-brown. Scape very short; pedicel subglobulose, slightly elongate.
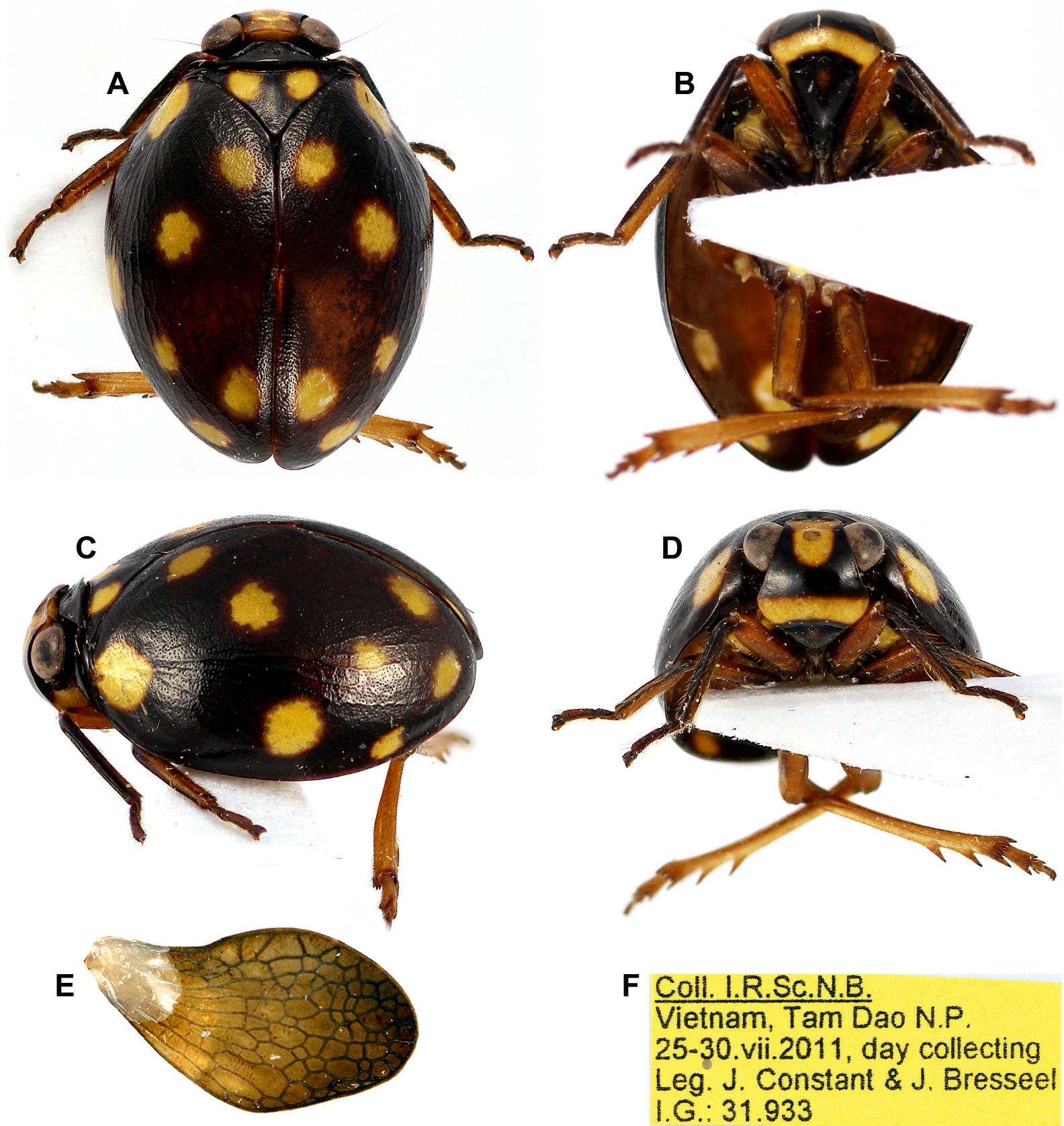

Fig. 3. Gergithus (Maculergithus) luteomaculatus subgen. et sp. nov., holotype, ${ }^{\lambda}$, total length: $6.4 \mathrm{~mm}$. A. Habitus, dorsal view. B. Habitus, ventral view. C. Habitus, lateral view. D. Habitus, frontal view. E. Right hind wing. F. Label. 


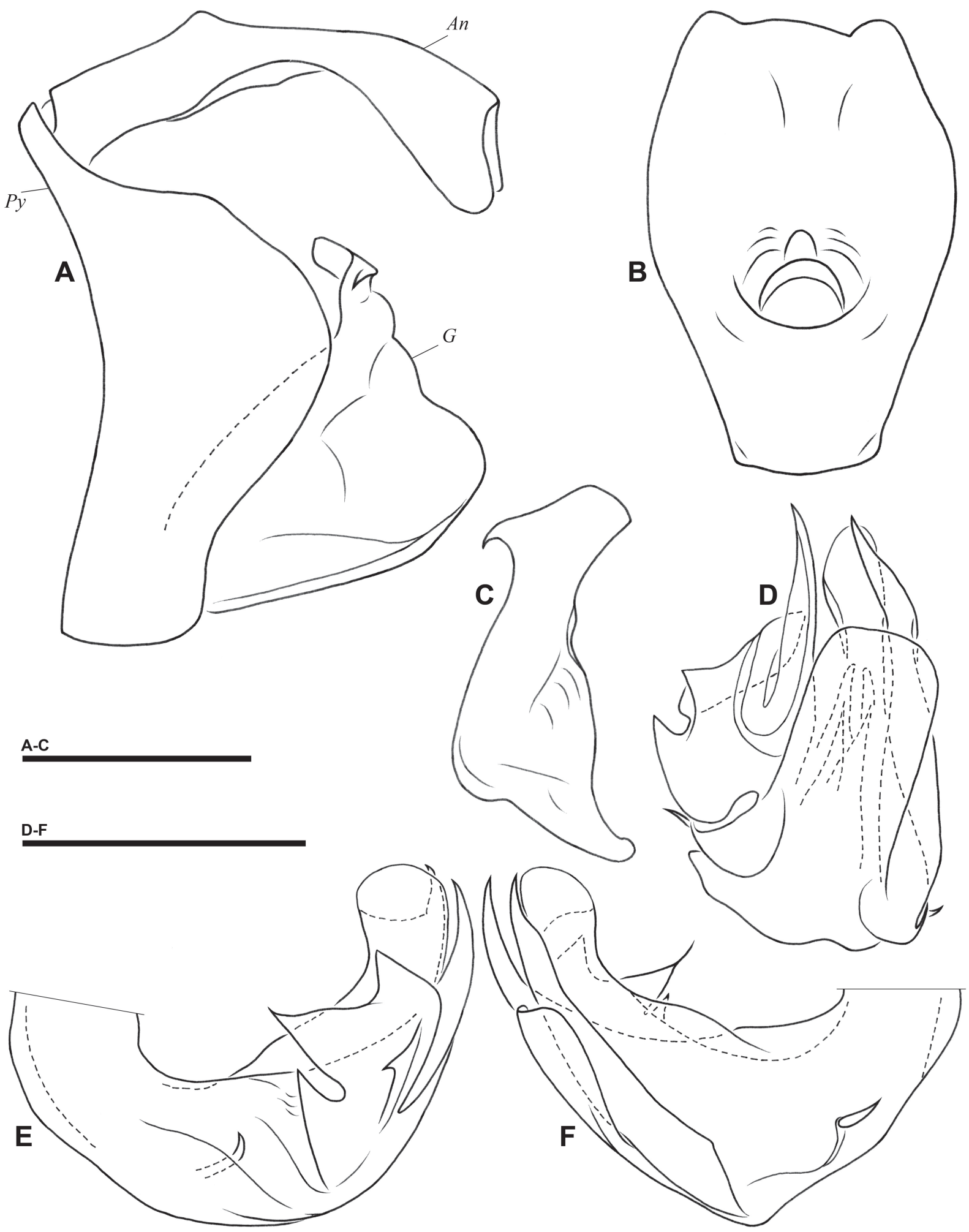

Fig. 4. Gergithus (Maculergithus) luteomaculatus subgen. et sp. nov., holotype, male genitalia. A. Pygofer, anal tube and gonostyli, left lateral view. B. Anal tube, dorsal view. C. Left gonostylus, posterior view. D. Aedeagus, postero-ventral view. E. Aedeagus, left lateral view. F. Aedeagus, right lateral view. Abbreviations: $A n=$ anal tube; $G=$ gonostyli; $P y=$ pygofer. Scale bars: $1 \mathrm{~mm}$. 
Thorax. Pronotum minutely punctured, with anterior margin slightly carinate behind head and 2 impressed points in middle; entirely black-brown (Fig. 3A, C). Mesonotum minutely punctured, with transverse carina along anterior margin; black-brown with round bright yellow spot on each side before lateral angle (Fig. 3A). Scutellum slightly wrinkled transversely (Fig. 3A). Tegulae black-brown (Fig. 3A, C).

Tegmina. (Fig. 3A, C) Black-brown, elongate, minutely punctured, with external margin broadly rounded and apical margin rounded. Reticulum of veins very slightly visible. Eight bright yellow spots organized, from base to apex: $1,1,1,1,1,2$, 1 , with 4 spots along costal margin and 2 spots along sutural margin.

Hind wings. (Fig. 3E) Brown, unilobed, with veins darker, slightly shorter than tegmina. Venation reticulate with main longitudinal veins distinct basally and numerous cross-veinlets. Costal margin strongly sinuate; sutural margin angularly rounded at mid-length and apical margin rounded.

Legs. (Fig. 3A-D) Elongate and slender. Pro- and mesocoxae black; metacoxae dark brown. Femora brown. Protibiae black-brown, paler on internoventral face; mesotibiae brown with externoventral carina black; metatibiae yellow-brown with 2 lateral spines near apex and 6 apical spines. Protarsi dark brown; mesotarsi brown; metatarsi yellow-brown. Metatibotarsal formula: (2) 6/7/2.

\section{Male genitalia}

Pygofer higher than broad and with posterior margin strongly sinuate and roundly projecting in middle in lateral view, and strongly narrowing dorsally (Fig. 4A). Gonostyli longer than high in lateral view (Fig. 4A) with capitulum well developed; capitulum apically laminate and projecting anterointernally; lateral spine of capitulum acute, hooked and projecting anteroventrally; ventroapical margin of gonostyli rounded in lateral view (Fig. 4A, C). Anal tube 1.45 times longer in median line than broad, dorsoventrally flattened and curved ventrally on posterior half; sides broadly rounded and apex truncate in middle (Fig. 4A-B); posterolateral angles projecting posteroventrally (Fig. 4A-B). Aedeagus strongly asymmetrical with ventral lobe of phallobase elongate, parallel-sided, slightly concave internally and roundly truncate apically (Fig. 4D, F). Lateroapical processes of phallobase elongate and spinose, nearly reaching apex of phallus; right process emarginate laterally towards apex (Fig. 4D-F). Left ventrolateral lobe of phallobase laminate and projecting laterally with 3 pointed processes projecting anterolaterally, the median one more developed, and another, more posterior pointed process projecting laterally (Fig. 4D-E). Small hook-shaped lateral process at basal half, on each side (Fig. 4 D-F). Right lateral lobe of phallobase laminate, slightly concave internally (Fig. 4F).

\section{Distribution}

Known from Vietnam, Vinh Phuc province, Tam Dao National Park. See map Fig. 1.

\section{Biology}

The specimens were collected on lower vegetation, in moist evergreen low mountain forest at an altitude around $1,000 \mathrm{~m}$ above sea level.

\section{Gergithus (Maculergithus) multipunctatus Che, Zhang \& Wang, 2007}

Figs $1,2 \mathrm{C}-\mathrm{D}$

Gergithus multipunctatus Che et al. 2007: 621 [described], figs 42-50 [head, thorax, tegmen, hind wing and male genitalia illustrated].

Gergithus multipunctatus - Meng \& Wang 2012: 4 [keyed], 8 [compared with G. nonopunctatus Meng \& Wang, 2012] — Chen et al. 2014: 4 [listed from China], 190 [distribution, material examined - see note infra]. 
non Gergithus multipunctatus - Chen et al. 2014: (erroneous: based on wrong identification of an undescribed species) 50 [keyed], 55 [described], 56 [habitus, details and male genitalia illustrated], 190 [material examined (see note infra) ] — Guo \& Chen 2015: (erroneous: based on wrong identification of an undescribed species) 430 [material examined], 431 [colour and ratios], 432-433 [male genitalia], figs 9-10, 17, 23, 29, 35 [habitus, frons and male genitalia illustrated].

\section{Note}

The illustrations of the species by Chen et al. (2014) and Guo \& Chen (2015) show strong discrepancies when comparing with the original description and accompanying illustrations provided by Che et al. (2007). The specimen illustrated in the two first papers shows a yellow vertex (instead of brown) and frons without yellow spot near dorsal margin. The illustrations of the male genitalia, despite their poor quality in the two first works, also show strong differences, especially obvious in the shape of the ventrolateral lobe of the phallobase which is much larger in Che et al. (2007).

The list of material examined by Chen et al. (2014) mentions only one male available for genitalia examination. It originates from Hainan, Wuzhishan, rather far from Jianfeng Mountain, the only surely recorded location for G. (Maculergithus) multipunctatus to date.

The concept of G. (Maculergithus) multipunctatus in Chen et al. (2014) and Guo \& Chen (2015) should not be taken as indicative of the species.

\section{Diagnosis}

The species can be recognized by the following combination of characters: (1) frons with a round yellow spot below dorsal margin, not reaching the latter; (2) vertex brown; (3) 4 yellow spots on tegmina along sutural margin; (4) tegmina with 10 yellow spots in total.

Identification can be confirmed by the male genitalia characters illustrated in Che et al. (2007: figs 4649).

\section{Distribution}

Known from China, Hainan: Jianfeng Mountain (Che et al. 2007) (see map Fig. 1).

\section{Remark}

The mention of the species in Hainan: Wuzhishan by Chen et al. (2014) is based on the misidentification of a yet undescribed species and hence erroneous.

\section{Gergithus (Maculergithus) nonomaculatus Meng \& Wang, 2012}

Figs 1, 2E-F

Gergithus nonomaculatus Meng \& Wang 2012: 4 [keyed], 5 [described], figs 1-18 [habitus, details, male and female genitalia illustrated].

Gergithus nonomaculatus - Chen et al. 2014: 4 [listed from China].

\section{Diagnosis}

The species can be recognized by the following combination of characters: (1) frons without yellow spot along dorsal margin; (2) vertex yellow; (3) 3 yellow spots on tegmina along sutural margin; (4) tegmina with 9 yellow spots in total.

Identification can be confirmed by the male genitalia characters illustrated in Meng \& Wang (2012: figs 16-18). 


\section{Distribution}

Known from China, Hainan, Bawangling Mountain (Meng \& Wang 2012) (see map Fig. 1).

Gergithus (Maculergithus) tamdao subgen. et sp. nov. urn:1sid:zoobank.org:act:4368D0A6-3C1D-42EB-91B2-59769EE60780

Figs 1, 2G-H, 5-6

\section{Diagnosis}

The species can be recognized on the following combination of characters: (1) frons with a yellow spot along dorsal margin; (2) vertex yellow; (3) 3 yellow spots on tegmina along sutural margin; (4) tegmina with 10 yellow spots in total.

\section{Etymology}

The species epithet refers to the type location, Tam Dao National Park in North Vietnam. It is used as a noun in apposition.

\section{Type material}

\section{Holotype}

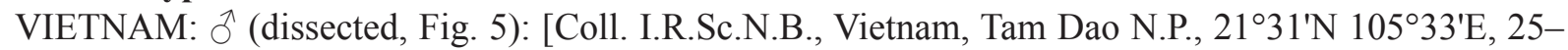
30.vii.2011, day collecting, Leg. J. Constant \& J. Bresseel, I.G.: 31.993] (RBINS).

\section{Paratype}

VIETNAM: 1 : : same data as holotype (VNMN).

\section{Description}

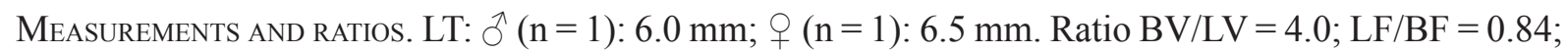
$\mathrm{LTg} / \mathrm{BTg}=1.73$.

HEAD. Vertex slightly excavate, bright yellow (Fig.5A). Frons smooth and convex, largely visible from above, black-brown with broad transverse bright yellow band slightly above clypeo-frontal suture, and rounded bright yellow spot along dorsal margin, not reaching dorsolateral angles (Fig. 5A-D). Genae black-brown, bright yellow under antennae (Fig. 5C). Clypeus smooth, slightly carinate subapically, black-brown (Fig. 5B, D). Labium dark brown, reaching median coxae, with last segment narrower and shorter than penultimate. Antennae black-brown. Scape very short; pedicel subglobulose, slightly elongate.

Thorax. Pronotum minutely punctured, with anterior margin slightly carinate behind head and 2 impressed points in middle; entirely black-brown (Fig. 5A, C). Mesonotum minutely punctured, with transverse carina along anterior margin; black-brown with round bright yellow spot on each side before lateral angle (Fig. 5A). Scutellum slightly wrinkled transversely (Fig. 5A). Tegulae black-brown (Fig. $5 \mathrm{~A}, \mathrm{C})$.

TEgmina. (Fig. 5A, C) Black-brown, elongate, minutely punctured, with external margin and apical margins rounded. Reticulum of veins very slightly visible. Ten bright yellow spots organized, from base to apex: 1, 2, 1, 2, 1, 2, 1, with 4 spots along costal margin and 3 spots along sutural margin.

HIND wINGs. Brown, unilobed, with veins darker, slightly shorter than tegmina. Venation reticulate with main longitudinal veins distinct basally and numerous cross-veinlets. Costal margin strongly sinuate; sutural margin angularly rounded at mid-length and apical margin rounded. 
LeGs. (Figs 5A-D) Elongate and slender. Pro- and mesocoxae black; metacoxae yellow-brown. Femora yellow-brown. Protibiae yellow-brown with anterodorsal and anteroventral carinae black; mesotibiae yellow-brown with externoventral carina black; metatibiae yellow-brown with 2 lateral spines near apex and 6 apical spines. Protarsi yellow-brown; mesotarsi and metatarsi yellow. Metatibotarsal formula: (2) $6 / 7 / 2$.
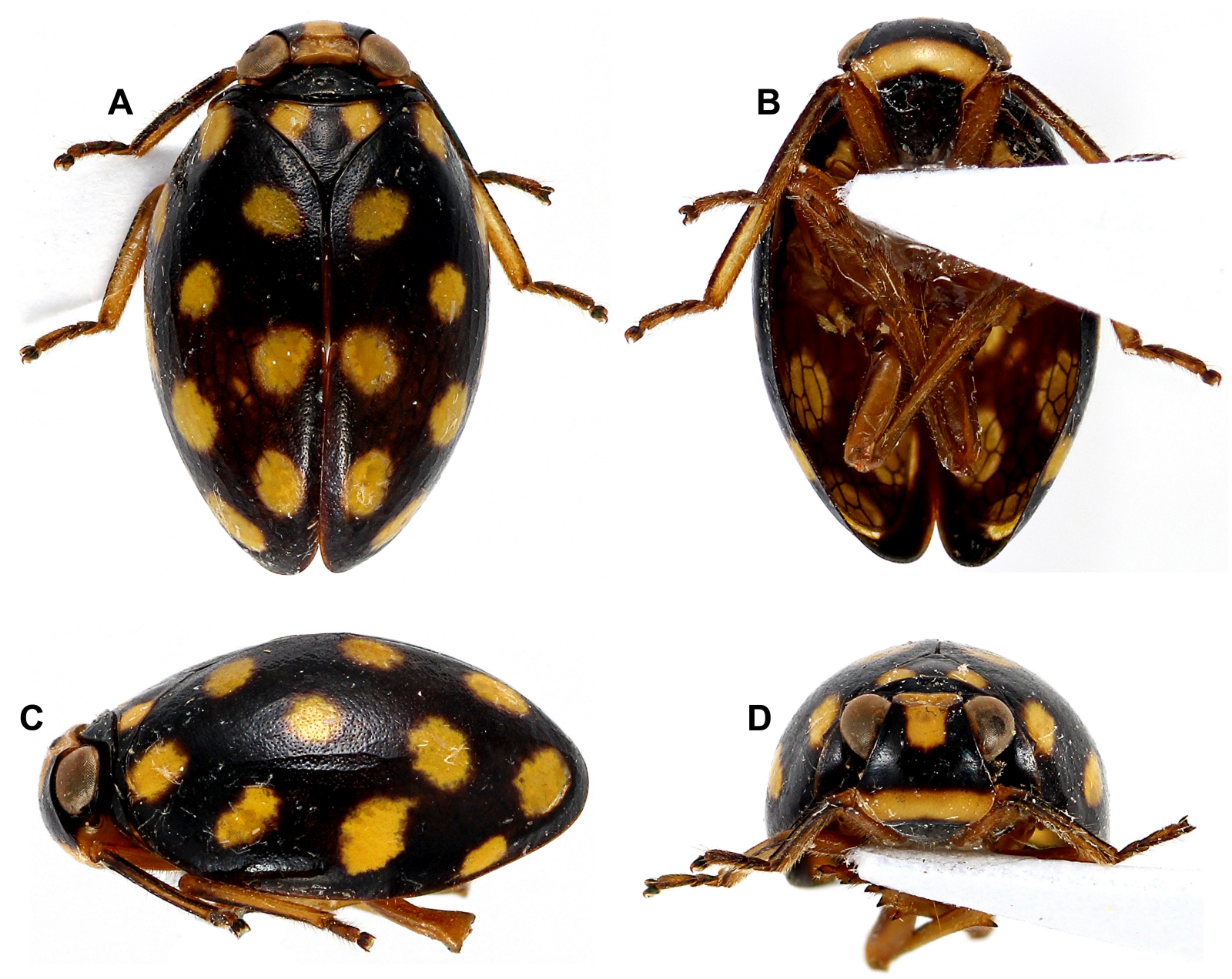

E

Coll.I.R.SC.N.B.

Vietnam, Tam Dao N.P. $21^{\circ} 31^{\prime} \mathrm{N} 105^{\circ} 33^{\prime} \mathrm{E}, 25$ 30.vii. 2011 day collecting Leg. J. Constant \& J. Bresseel, I.G.: 31.993

Fig. 5. Gergithus (Maculergithus) tamdao subgen. et sp. nov., holotype, $\widehat{\partial}$, total length: $6.0 \mathrm{~mm}$. A. Habitus, dorsal view. B. Habitus, ventral view. C. Habitus, lateral view. D. Habitus, frontal view. E. Label. 


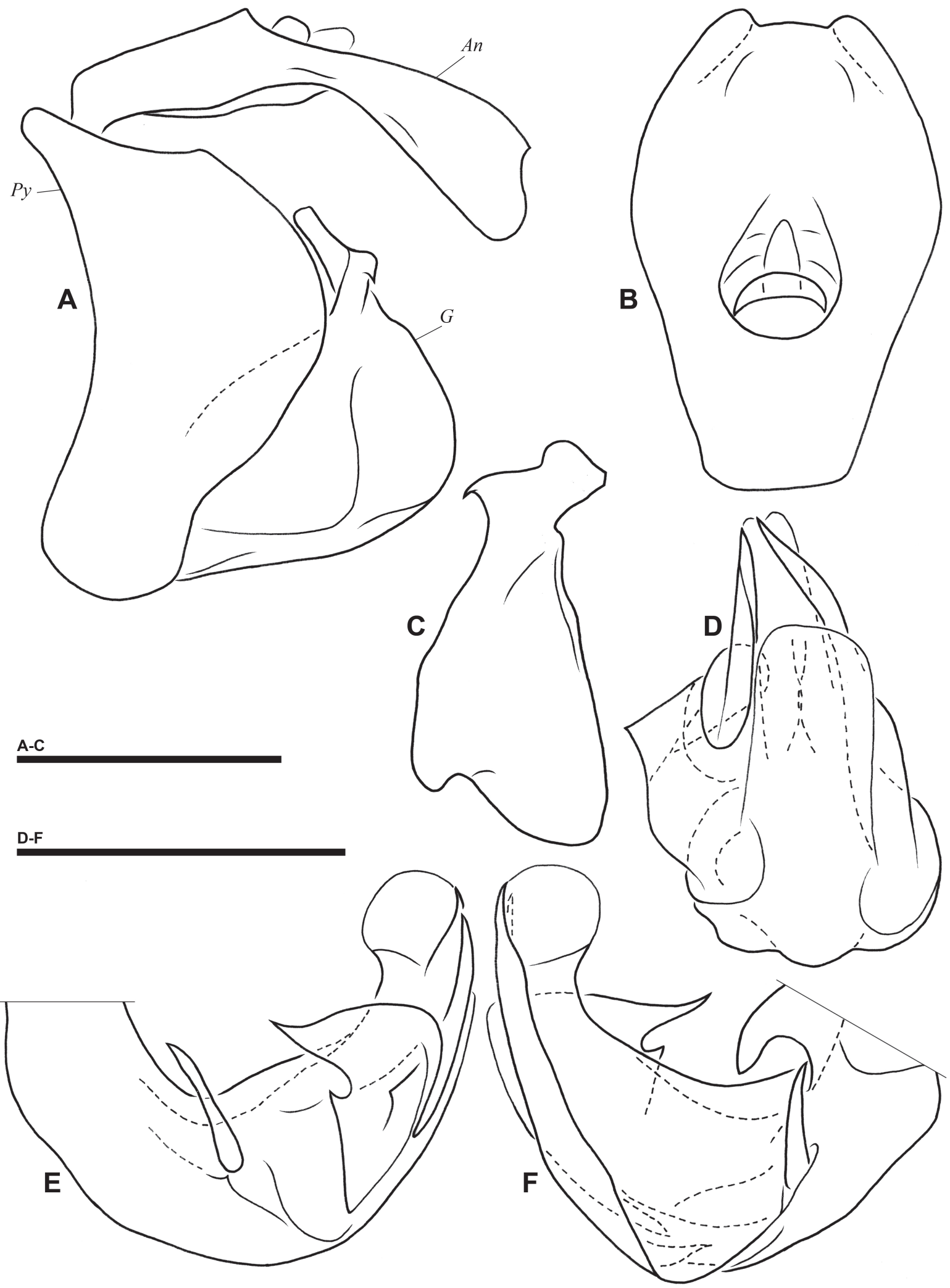

Fig. 6. Gergithus (Maculergithus) tamdao subgen. et sp. nov., holotype, male genitalia. A. Pygofer, anal tube and gonostyli, left lateral view. B. Anal tube, dorsal view. C. Left gonostylus, posterior view. D. Aedeagus, postero-ventral view. E. Aedeagus, left lateral view. F. Aedeagus, right lateral view. Abbreviations: $A n=$ anal tube; $G=$ gonostyli; $P y=$ pygofer. Scale bars: $1 \mathrm{~mm}$. 


\section{Male genitalia}

Pygofer higher than broad and with posterior margin strongly sinuate and roundly projecting in middle in lateral view, and emarginate dorsally (Fig. 6A). Gonostyli slightly longer than high in lateral view (Fig. 6A) with capitulum well developed; capitulum apically laminate and projecting anterointernally; lateral spine of capitulum acute, hooked and projecting lateroventrally; ventroapical margin of gonostyli rounded in lateral view (Fig. 6A, C). Anal tube 1.5 times longer in median line than broad, dorsoventrally flattened and curved ventrally on posterior half; sides broadly rounded and apex truncate in middle (Fig. 6A-B); posterolateral angles projecting posteroventrally (Fig. 6A-B). Aedeagus strongly asymmetrical with ventral lobe of phallobase elongate, parallel-sided, and roundly truncate apically (Fig. 6D). Lateroapical processes of phallobase elongate and spinose, nearly reaching apex of phallus; right process sinuate internally towards apex (Fig. 6D-F). Left ventrolateral lobe of phallobase laminate and projecting laterally with 2 pointed processes projecting anterolaterally, the dorsal one much more developed, and another more posterior pointed process projecting laterally (Fig. 6D-E). Rather long, spinose lateral process at basal half, on each side, projecting dorsoanteriorly (Fig. 6D-F). Right lateral lobe of phallobase laminate, slightly concave internally (Fig. 6F).

\section{Distribution}

Known from Vietnam, Vinh Phuc province, Tam Dao National Park (see map Fig. 1).

\section{Biology}

The specimens were collected on lower vegetation, in moist evergreen low mountain forest at an altitude around $1000 \mathrm{~m}$ above sea level.

\section{Gergithus (Maculergithus) sp.}

Figs 1, 2I-J

Gergithus multipunctatus - Chen et al. 2014 (erroneously identified as G. multipunctatus Che, Zhang \& Wang, 2007): 50 [keyed], 55 [described], 56 [habitus, details and male genitalia illustrated], 190 [material examined - see note infra] — Guo \& Chen 2015 (erroneously identified as G. multipunctatus Che, Zhang \& Wang, 2007): 430 [material examined], 431 [colour and ratios], 432-433 [male genitalia], figs 9-10, 17, 23, 29, 35 [habitus, frons and male genitalia illustrated].

\section{Diagnostic characters}

The species can be recognized on the following combination of characters: (1) frons without yellow spot along dorsal margin; (2) vertex yellow; (3) 3 yellow spots on tegmina along sutural margin; (4) tegmina with 10 yellow spots in total.

\section{Distribution}

Known from China, Hainan, Wuzhishan (Meng \& Wang 2012) (see map Fig. 1).

\section{Discussion}

Including the 2 species described in this paper, the genus Gergithus now contains 62 species. The new subgenus Maculergithus subgen. nov. is the first cut proposed inside the genus while it is obvious that other groups of species exist within the genus. As an example, there is a group of new species (Constant unpublished data) very closely related to G. gravidus Melichar, 1906, which form a very consistent natural group with the latter.

The currently known distribution of Gergithus (Maculergithus) is restricted to Hainan Island in SE China and the Tam Dao massif in northern Vietnam. This distribution pattern is similar to the one 
observed in other Issidae like e.g. Pseudochoutagus Che, Zhang \& Wang, 2011 (Hainan and Tam Dao Che et al. 2011; Gnezdilov \& Constant 2012) and Neogergithoides Sun, Meng \& Wang, 2012 (Hainan, mountains of SE China and mountains of N Vietnam - Sun et al. 2012; Constant \& Pham 2015). It seems worth mentioning that Hainan and Tam Dao are prospected by entomologists on a regular basis and hence it is likely that further exploration of the less known mountains of N Vietnam and SE China (especially Yunnan and Guangdong provinces, and Guangxi autonomous region in China) will reveal a number of additional species. The apparently restricted distribution of the species (see Fig. 1) in Hainan and the fact that species can occur sympatrically (as in Tam Dao) are additional clues which encourage the taxonomic prospection in the region.

\section{Acknowledgments}

We thank Mr Joachim Bresseel (collaborator, RBINS) and Mr Vu Tru Hoang (Institute of Ecology and Biological Resources, Hanoi, Vietnam) for their company and enthusiasm during our fieldwork in Vietnam; Dr Patrick Grootaert (RBINS) for his permanent support to our projects; Mr Julien Caudron (RBINS) for the drawings illustrating the key. Our project in Vietnam is supported through a grant issued by the capacity building Programme of the Belgian Global Taxonomic Initiative National Focal Point that runs with financial support from the Belgian Directorate-General for Development Cooperation.

\section{References}

Bourgoin T. 2016. FLOW (Fulgoromorpha Lists on The Web): A world knowledge base dedicated to Fulgoromorpha. V.8, updated [8 January 2016]. Available from http://hemiptera-databases.org/flow/ [accessed 8 Jan. 2016]

Carayon J. 1969. Emploi du noir chlorazol en anatomie microscopique des insectes. Annales de la Société entomologique de France (N.S.) 5: 179-193.

Chan M.-L. \& Yang C.-T. 1994. Issidae of Taiwan (Homoptera: Fulgoroidea). Chen Chung Book Press, Taichung.

Che Y.-L, Zhang Y.-L. \& Wang Y.-L. 2007. Seven new species and one new record of Gergithus Stål (Hemiptera: Fulgoroidea: Issidae) from China. Proceedings of the Entomological Society of Washington 109 (3): 611-627.

Che Y.-L., Zhang Y.-L. \& Wang Y.-L. 2011. A new genus of the tribe Issini Spinola (Hemiptera: Fulgoroidea: Issidae) from China. Zootaxa 3060: 62-66.

Chen X.-S., Zhang Z.-G. \& Chang Z. 2014. Issidae and Caliscelidae from China. Guizhou Science and Technology Publishing House, Guiyang.

Constant J. 2004. Révision des Eurybrachidae (I). Le genre Amychodes Karsch, 1895 (Homoptera: Fulgoromorpha: Eurybrachidae). Bulletin de l'Institut royal des Sciences naturelles de Belgique 74: $11-28$.

Constant J. \& Pham H.T. 2015. Two new species of the genus Neogergithoides Sun, Meng \& Wang, 2012 extend its distribution to Northern Vietnam (Hemiptera: Fulgoromorpha: Issidae). Belgian Journal of Entomology 33: 1-15.

Fennah R.G. 1978. Fulgoroidea (Homoptera) from Vietnam. Annales Zoologici Warszawa 34 (9): 207279.

Gnezdilov V.M. \& Constant J. 2012. Review of the family Issidae (Hemiptera: Fulgoromorpha) in Vietnam with description of a new species. Annales Zoologici 62 (4): 571-576. http://dx.doi. org/10.3161/000345412X659632 
Gnezdilov V.M., Bourgoin T. \& Soulier-Perkins A. 2014. Vietnamese Issidae (Hemiptera, Fulgoroidea): new taxa, new records and new distribution data. Zootaxa 3847 (1): 80-96. http://dx.doi.org/10.11646/ zootaxa.3847.1.4

Guo M. \& Chen X.-S. 2015. Morphological comparison on six male Gergithus (Fulgoroidea, Issidae) from China. Sichuan Journal of Zoology 34 (3): 429-434.

Holt B.G., Lessard J.-P., Borregaard M.K., Fritz S.A., Araújo M.B., Dimitrov D., Fabre P.-H., Graham C.H., Graves G.R., Jønsson K.A., Nogués-Bravo D., Wang Z., Whittaker R.J., Fjeldså J. \& Rahbek C. 2013. An update of Wallace's zoogeographic regions of the World. Science 339 (6115): 74-78. http:// dx.doi.org/10.1126/science. 1228282

Hori Y. 1969. Hemisphaeriinae of the Japan Archipelago (Hemiptera: Issidae). Transactions of the Shikoku Entomological Society, 10 (2), 49-64.

Melichar L. 1906. Monographie der Issiden (Homoptera). Abhandlungen der K. K. Zoologischbotanischen Gesellschaft in Wien, 3 (4): 1-327.

Meng R. \& Wang Y. 2012. Two new species of the genus Gergithus Stål (Hemiptera: Fulgoromorpha: Issidae) from China, with a redescription of G. bimaculatus Zhang and Che, and G. tessellatus Matsumura. Zootaxa 3247: 1-18.

Stål C. 1855. Nya Hemiptera. Ofversigt af Kongliga Svenska Vetenskaps-Akademiens Förhandlingar. Stockholm 12: 181-192. http://biodiversitylibrary.org/page/15969933

Stål C. 1870. Hemiptera insularum Philippinarum. - Bidrag till Philippinska öarnes Hemipterfauna. Öfversigt af Kongliga Svenska Vetenskaps-Akademiens Förhandlingar 27: 607-756. http:// biodiversitylibrary.org/page/24634225

Sun Y., Meng R. \& Wang Y. 2012. Neogergithoides, a new genus with a new species from China (Hemiptera: Issidae). Zootaxa 3186: 42-53.

Zhang Y. \& Che Y.-L. 2009. Checklist of Gergithus Stal (Hemiptera: Issidae: Hemisphaeriinae) with descriptions of two new species from China. Entomotaxonomia 31 (3): 181-187.

Manuscript received: 9 December 2015

Manuscript accepted: 12 January 2016

Published on: 19 May 2016

Topic editor: Koen Martens

Desk editor: Kristiaan Hoedemakers

Printed versions of all papers are also deposited in the libraries of the institutes that are members of the EJT consortium: Muséum national d'Histoire naturelle, Paris, France; Botanic Garden Meise, Belgium; Royal Museum for Central Africa, Tervuren, Belgium; Natural History Museum, London, United Kingdom; Royal Belgian Institute of Natural Sciences, Brussels, Belgium; Natural History Museum of Denmark, Copenhagen, Denmark. 